\title{
Investigation of mechanisms involved in germination enhancement of wheat (Triticum aestivum) by cold plasma: Effects on seed surface chemistry and characteristics
}

\author{
Agata Los \\ Technological University Dublin, agata.los@tudublin.ie \\ Dana Ziuzina \\ Technological University Dublin, dana.ziuzina@tudublin.ie \\ Daniela Boehm \\ Technological University Dublin, daniela.boehm@tudublin.ie
}

See next page for additional authors

Follow this and additional works at: https://arrow.tudublin.ie/schfsehart

Part of the Agronomy and Crop Sciences Commons, and the Food Science Commons

\section{Recommended Citation \\ Los, A, Ziuzina, D, Boehm, D, Cullen, PJ, Bourke, P. Investigation of mechanisms involved in germination enhancement of wheat (Triticum aestivum) by cold plasma: Effects on seed surface chemistry and characteristics. Plasma Process Polym. 2019; 16:e1800148, DOI: 10.1002/ppap.201800148}

This Article is brought to you for free and open access by the School of Food Science and Environmental Health at ARROW@TU Dublin. It has been accepted for inclusion in Articles by an authorized administrator of ARROW@TU

Dublin. For more information, please contact

arrow.admin@tudublin.ie, aisling.coyne@tudublin.ie, gerard.connolly@tudublin.ie.

Funder: Science Foundation Ireland

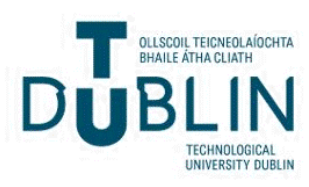




\section{Authors}

Agata Los, Dana Ziuzina, Daniela Boehm, Patrick J. Cullen, and Paula Bourke 


\title{
Investigation of mechanisms involved in germination enhancement of wheat (Triticum aestivum) by cold plasma: Effects on seed surface chemistry and characteristics
}

\author{
Agata Los $^{1}$ ～Dana Ziuzina ${ }^{1}$ | Daniela Boehm ${ }^{1}$ | Patrick J. Cullen ${ }^{1,2}$ | \\ Paula Bourke ${ }^{1}$
}

${ }^{1}$ Plasma Research Group, School of Food Science and Environmental Health, Technological University Dublin, D01 HV58, Dublin 1, Ireland

${ }^{2}$ Department of Chemical and Environmental Engineering, University of Nottingham, NG7 2RD, Nottingham, United Kingdom

\section{Correspondence}

Paula Bourke, School of Food Science and Environmental Health, Technological University Dublin, Marlborough Street, Dublin 1, Ireland.

Email: paula.bourke@dit.ie

Funding information

Science Foundation Ireland, Grant number: $14 / \mathrm{IA} / 2626$
Recent reports indicate that atmospheric cold plasma (ACP) treatment of seeds can enhance their germination, however, the mechanisms of action are not yet entirely clear. In the present work, we report on the effects of plasma treatment on wheat seed germination and seedling growth. Additionally, changes in the surface chemistry and characteristics of the wheat seeds exposed to plasma were investigated. Treatments of 30-60 s significantly enhanced the germination rate and showed positive effects on seedling growth. ACP resulted in changes of seed surface and chemical characteristics including water uptake and contact angle values. Changes in seed $\mathrm{pH}$ and total titratable acidity, as well as nitrites, nitrates, and malondialdehyde concentrations were also recorded.

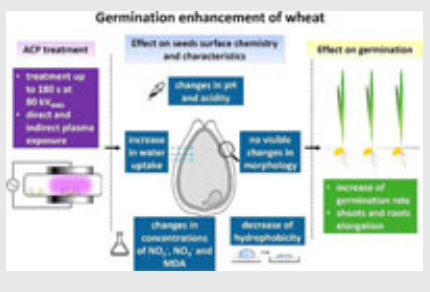

\section{K E Y W OR D S}

cold plasma, dielectric barrier discharges (DBD), food quality, seed germination, wheat seeds

\section{1 | INTRODUCTION}

The first cultivation of wheat (Triticum spp.) occurred about 10000 years ago, as a part of the Neolithic Revolution, which saw a transition from a hunter-gatherer lifestyle to dependence on agricultural production. Since then wheat has been the basic staple food of the major civilizations globally. ${ }^{[1]}$ With over 700 million tonnes harvested annually, wheat is one of the most important crops in the world, used both for human food and livestock feed. ${ }^{[2]}$ The nutritional value of wheat is due to its high content of proteins and carbohydrates, as well as considerable proportions of vitamins (thiamine and vitamin-B) and minerals (zinc, iron). Wheat is also a good source of trace minerals like selenium and magnesium. ${ }^{[3,4]}$
A gradual but consistent increase in global wheat consumption is largely driven by population growth and rising household income in developing and emerging economies. ${ }^{[5]}$ It is predicted that if the demand growth rate remains constant, the global wheat consumption will surpass 880 million metric tonnes by $2050 .{ }^{[6]}$ Therefore, it is necessary to improve crop production techniques and enhance the germination of wheat seed. Several techniques have been evaluated for the potential germination improvement of wheat, including ultrasound treatment, ${ }^{[7]}$ magnetic fields, ${ }^{[8,9]}$ irradiation, ${ }^{[10,11]}$ exposure to titanium dioxide nanoparticles nano- $\mathrm{TiO}_{2},{ }^{[12]}$ and cold plasma technology. ${ }^{[13-16]}$

Recent evidence indicates that cold plasma treatment of seeds can enhance their germination as well as seedling growth. The effectiveness of the treatment was shown to be 
dependent of the type of seed, their condition, as well as environmental factors, including climate, soil conditions, and water availability. ${ }^{[17]}$ Seed germination improvement by cold plasma technology is not only beneficial for agriculture applications, but also in food processing sector with the malting, brewing, weaning foods, and specialty flours industries relying on germination as a major operation. Technologies which can enhance germination could significantly reduce energy usage, thereby contributing toward sustainability in food. ${ }^{[18]}$

Although several effects of cold plasma on the physiological and biochemical properties of seeds have been reported, ${ }^{[19,20]}$ the mechanisms resulting in enhancement of seed germination and promoting the growth of the plants, are not entirely clear. The overall result can be a combination of various factors such as changes in seed surface wettability and increases in water absorption, ${ }^{[13,21]}$ seed coat erosion, ${ }^{[22]}$ removal of microbial contamination, ${ }^{[17]}$ and changes in hormonal activities associated with plant signaling and development. ${ }^{[23]}$ Cold plasma processing possess many advantages in agriculture - it operates at low temperatures and short processing times, without inducing damage to crops, foods, seeds, humans, and the environment. ${ }^{[18]}$ However, as several studies have reported chemical changes to food components following plasma treatment, it is necessary to understand the biochemical interactions with food systems to determine and control the optimum plasma process designs for agriculture and food. ${ }^{[24,25]}$

The aim of this work was to provide insights into the enhancement of seeds germination and seedling growth of wheat by cold plasma technology. The objectives of the study were: (1) to investigate the influence of ACP treatment parameters on seed germination and seedling growth; (2) to assess changes of seed surface properties following plasma treatment by measurements of water uptake, moisture content, and water contact angle; (3) to explore changes of seed surface chemistry by measurements of seed $\mathrm{pH}$ and acidity, as well as the content of compounds which could potentially be altered by ACP treatment (hydrogen peroxide, nitrites, nitrates, and malondialdehyde); and (4) to investigate if ACP treatment induces changes in seed surface morphology by performing SEM analysis.

\section{2 | EXPERIMENTAL SECTION}

\section{1 | Seed material}

Organic wheat seeds (Triticum aestivum L., origin: Ireland) were purchased from a local retailer. Only healthy seeds without visible defects or signs of infection were selected for the studies.

\section{2 | Plasma system}

Plasma treatment was performed using a high-voltage dielectric barrier discharge atmospheric cold plasma system with a maximum output of $120 \mathrm{kV}_{\mathrm{RMS}}$ at $50 \mathrm{~Hz}$ which has been described in detail. ${ }^{[26,27]}$

\section{3 | Plasma treatment}

Petri dishes $(92 \times 16 \mathrm{~mm})$ containing $2 \mathrm{~g}$ (i.e., $\sim 60$ seeds) of wheat seeds were placed inside the polypropylene container, which was sealed with air-tight film. Samples were placed either directly in the area of discharge between high voltage and ground electrode (direct treatment) or within the sealed reactor but outside of the area of discharge (indirect treatment). ${ }^{[28]}$ Seeds were exposed to $80 \mathrm{kV}_{\mathrm{RMS}}$ plasma treatment under atmospheric pressure using atmospheric air as a working gas for either 30,60 , or $180 \mathrm{~s}$ and analyzed immediately or stored for $24 \mathrm{~h}$ at $15{ }^{\circ} \mathrm{C}$ to monitor the effect of extended contact time with the confined plasma-generated reactive species. Untreated control seeds were stored under identical conditions as ACP-treated seeds. Each ACP treatment was performed at least three times.

\subsection{Seed germination and characteristics of seedling growth}

Plasma-treated and control wheat seeds were transferred into plastic seed trays containing one layer of filter paper moistened with $20 \mathrm{ml}$ of sterile deionized water (Day 0). The trays were covered with plastic wrap to keep the moisture levels constant. Samples were incubated at room temperature in the dark for 7 days at relative humidity of $55-65 \%$ and temperature of $22-25{ }^{\circ} \mathrm{C}$. In order to maintain sufficient moisture for germination, 10 and $20 \mathrm{ml}$ of deionized water were added during the experiment on the first and third day of the test, respectively. The germination percentage was measured on the second, third, and seventh day using radicle extrusion as a criterion where a seed is considered germinated if the radicle length was $\geq 2 \mathrm{~mm} .{ }^{[29]}$ Germination experiments were performed four times; number of seeds per experiment $80(n=320)$. Each sample was cultivated in a separate plastic seed tray. Additionally, on the seventh day the length of the shoots and roots of 20 randomly selected germinated seeds from each sample were measured (every fourth germinated seed on the tray).

Estimated values were germination rate $(G \%)$, germination index (GI), and seed vigour index (SVI), calculated according to Equation $(1),{ }^{[13]}(2),{ }^{[30]}$ and $(3),{ }^{[31]}$ respectively:

$$
\begin{gathered}
G \%=(n \times 100 \%) / N \\
\text { GI }=\sum n / d
\end{gathered}
$$




$$
\mathrm{SVI}=\mathrm{GI} \times S
$$

where $n$ - number of seeds germinated on day $d, N$ - total number of seeds, $d$ is the number of days from the beginning of the test, and $S$ is the shoot length.

\section{$2.5 \mid$ Contact angle measurements}

To investigate aby-induced changes in the hydrophobicity of the wheat seed surface after plasma treatment, the apparent contact angles of deionized water (Sigma-Aldrich, Ireland) were measured as changes in the contact angle using the sessile drop technique (Theta Lite Optical Tensiometer, Biolin Scientific, UK). Analysis was performed immediately after deposition of a single droplet on the seed surface; average volume of a water droplet was $8.56 \pm 1.62 \mu \mathrm{l}$. The images were recorded at 15 frames per second for $10 \mathrm{~s}$ and analyzed using the OneAttension software (v 2.1) ${ }^{[32]}$ All the values reported are the mean of more than 100 data points done in triplicate (three randomly selected seeds).

\section{6 | Moisture content}

Moisture content of wheat seeds was determined by the oven drying method based on the loss of weight when drying under controlled conditions in an oven. ${ }^{[33]}$ Seeds were dried at $105^{\circ} \mathrm{C}$ for $24 \mathrm{~h}$. To calculate seed moisture content, the following formula was used:

$$
\mathrm{MC}=\left(w_{\mathrm{i}}-w_{\mathrm{f}}\right) \times 100 \% / w_{\mathrm{i}},
$$

where MC is moisture content of seeds (\% wet basis), $w_{\mathrm{i}}$ is initial mass of the sample (before drying), and $w_{\mathrm{f}}$ is final mass of the sample (after drying).

\section{$2.7 \mid$ Seed pH and acidity}

$2 \mathrm{~g}$ of seeds were homogenized using a Nutribullet blender (model NB-101B) to obtain a fine and homogeneous flour that subsequently was mixed with $50 \mathrm{ml}$ of deionized water (average $\mathrm{pH}-5.78 \pm 0.03$ ). The $\mathrm{pH}$ was determined by potentiometric measurement of the suspensions at $25^{\circ} \mathrm{C}$ using an Orion $\mathrm{pH}$ meter (model 420A). Total titratable acidity (TTA) was determined potentiometrically by titrating the suspensions with $0.1 \mathrm{M}$ sodium hydroxide $(\mathrm{NaOH}$; Sigma-Aldrich) to a final value of $\mathrm{pH} 8.1$ and was expressed as the amount of $\mathrm{NaOH}(\mathrm{ml})$ used.

\section{8 | Water uptake}

The effects of plasma on water uptake was measured according to the procedure described by Zahoranova et al. ${ }^{[16]}$ with minor modifications. Briefly, $2 \mathrm{~g}$ ( $\sim 60$ seeds) of untreated and ACP-treated seeds were weighed on an electronic balance to the nearest $0.1 \mathrm{mg}$, hydrated with $20 \mathrm{ml}$ of deionized water, and incubated at $25^{\circ} \mathrm{C}$. After 2 and $8 \mathrm{~h}$ of the imbibition process, the seeds were blotted dry and weighed to the nearest $0.1 \mathrm{mg}$. Water uptake (WU) was determined as an increase in seed weight and was expressed in $\mathrm{mg} / \mathrm{seed}$ according to the following equation:

$$
\mathrm{WU}=(\mathrm{FW}-\mathrm{DW}) / 60,
$$

where FW is fresh weight $[\mathrm{mg}]$ and DW is dry weight $[\mathrm{mg}]$ of the seeds.

\section{9 | Measurement of hydrogen peroxide $\left(\mathrm{H}_{2} \mathrm{O}_{2}\right)$, nitrite $\left(\mathrm{NO}_{2}{ }^{-}\right)$, nitrate $\left(\mathrm{NO}_{3}{ }^{-}\right)$, and malondialdehyde (MDA) concentrations}

The concentrations of hydrogen peroxide $\left(\mathrm{H}_{2} \mathrm{O}_{2}\right)$, nitrite $\left(\mathrm{NO}_{2}{ }^{-}\right)$, nitrate $\left(\mathrm{NO}_{3}{ }^{-}\right)$, and MDA in untreated and ACPtreated seeds were compared. $2 \mathrm{~g}$ of seeds were homogenized to a fine and homogeneous flour. The sample of flour $(0.5 \mathrm{~g})$ was mixed with $5 \mathrm{ml}$ of either $20 \%$ (w/v) trichloroacetic acid (TCA; Sigma-Aldrich) (analysis of $\mathrm{H}_{2} \mathrm{O}_{2}$ or MDA) or deionized water (analysis of $\mathrm{NO}_{2}{ }^{-}$or $\mathrm{NO}_{3}{ }^{-}$). The samples were centrifuged at $3500 \times g$ for $20 \mathrm{~min}$ and aliquot of the supernatant was used for the further analyses.

Hydrogen peroxide $\left(\mathrm{H}_{2} \mathrm{O}_{2}\right)$ concentration measurement was based on the oxidation of potassium iodide (KI; SigmaAldrich) to iodine and spectrophotometric measurement at

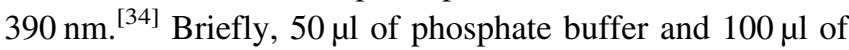
$1 \mathrm{M} \mathrm{KI}$ solution were added to $50 \mu \mathrm{l}$ of sample. After $30 \mathrm{~min}$ incubation, absorbance was read on a spectrophotometric plate reader at $390 \mathrm{~nm}$.

The concentration of nitrite $\left(\mathrm{NO}_{2}{ }^{-}\right)$was determined using Griess reagent (Sigma-Aldrich). ${ }^{[35]} 100 \mu \mathrm{l}$ Griess reagent was added to $100 \mu \mathrm{l}$ of sample. After $30 \mathrm{~min}$ incubation, absorbance was read at $548 \mathrm{~nm}$. Results were expressed as $\mu \mathrm{mol} \mathrm{g}{ }^{-1}$ seed.

The concentration of nitrate $\left(\mathrm{NO}_{3}{ }^{-}\right)$was determined photometrically by 2,6-dimethyl phenol (DMP) using the Spectroquant nitrate assay kit (Merck, Germany). Samples were pre-treated with sulfamic acid to eliminate nitrite interference. Results were expressed as $\mu \mathrm{mol} \mathrm{g}^{-1}$ seed.

A standard curve of known $\mathrm{H}_{2} \mathrm{O}_{2}$ ([Perhydrol $\left.{ }^{\circledR}\right]$ for analysis EMSURE ${ }^{\circledR}$ ISO), $\mathrm{NO}_{2}{ }^{-}$(sodium nitrite, SigmaAldrich), and $\mathrm{NO}_{3}{ }^{-}$(sodium nitrate, Sigma-Aldrich) concentrations was included on each plate and used to convert absorbance into the concentration values.

To determine MDA concentrations, the thiobarbituric acid (TBA) test was used. ${ }^{[36]} 0.5 \mathrm{ml}$ of the sample was 
mixed with $0.5 \mathrm{ml}$ of $20 \%$ TCA containing $0.5 \%$ (w/v) TBA (Sigma-Aldrich) and $25 \mu \mathrm{l} \%$ (w/v) butylated hydroxytoluene (BHT; Sigma-Aldrich) in ethanol. The mixture was heated at $95^{\circ} \mathrm{C}$ for $30 \mathrm{~min}$ and then cooled on ice. The samples were centrifuged at $10000 \times g$ for $15 \mathrm{~min}$ and the absorbance was measured at $532 \mathrm{~nm}$. The value for nonspecific absorption at $600 \mathrm{~nm}$ was subtracted. The concentration of MDA was calculated using an extinction coefficient of $155 \mathrm{mM}^{-1} \mathrm{~cm}^{-1}$. Results were expressed as $\mathrm{nmol} \mathrm{g}^{-1}$ seed.

\subsection{0 | Scanning electron microscopy (SEM)}

The effect of ACP treatment on wheat seed was analyzed by SEM. Samples were prepared according to the procedure described by Ziuzina et al. ${ }^{[37]}$ and examined visually using a FEI Quanta three-dimensional FEG Dual Beam SEM (FEI Ltd., Hillsboro, USA) at $5 \mathrm{kV}$.

\subsection{1 | Statistical analysis}

Statistical analysis was performed using SPSS statistics 21 Software (SPSS Inc., Chicago, USA). The values of germination parameters and seeds characteristics following ACP treatment were subjected to analysis of variance (ANOVA). Means of ACP-treated and untreated controls were compared according to the method of Fisher's Least Significant Difference-LSD at the 0.05 level.

\section{3 | RESULTS AND DISCUSSION}

\section{1 | Effect of ACP treatment on germination of wheat seeds}

In the present study, a stimulative effect of short duration of plasma treatment on germination parameters of wheat seed was noted. Similar trends were observed for plasma treatments employing either 0 or $24 \mathrm{~h}$ post-treatment retention times of the generated species within the reactor, however, the germination rate values were higher for seeds stored in the reactive environment for $24 \mathrm{~h}$ compared to the seeds planted without such a species exposure (Table 1). Regardless to posttreatment retention time ( 0 or $24 \mathrm{~h}$ ), the longest treatment time used in the study, i.e., $180 \mathrm{~s}$, had a negative effect on germination and significantly decreased germination rate measured on Day 2 (both direct and indirect modes of exposure) and Day 3 (direct exposure). No differences between germination rates of samples treated for $180 \mathrm{~s}$ and untreated seeds were noted after 7 days. For samples without a post-treatment retention time, the germination rate of seeds treated for $30 \mathrm{~s}$ with direct mode of exposure at the end of the test (day 7) was significantly higher (7.5\%) compared to samples not subjected to plasma, while significant increases of 8.9 and $9.4 \%$ were noted for 30 and $60 \mathrm{~s}$ of indirect treatment, respectively. Similarly, ACP treatment combined with $24 \mathrm{~h}$ of retention resulted in a significantly improved germination, with the measured differences observed on Day 3 retaining significantly higher values than the control

TABLE 1 Effect of ACP treatment on germination rate of wheat seeds

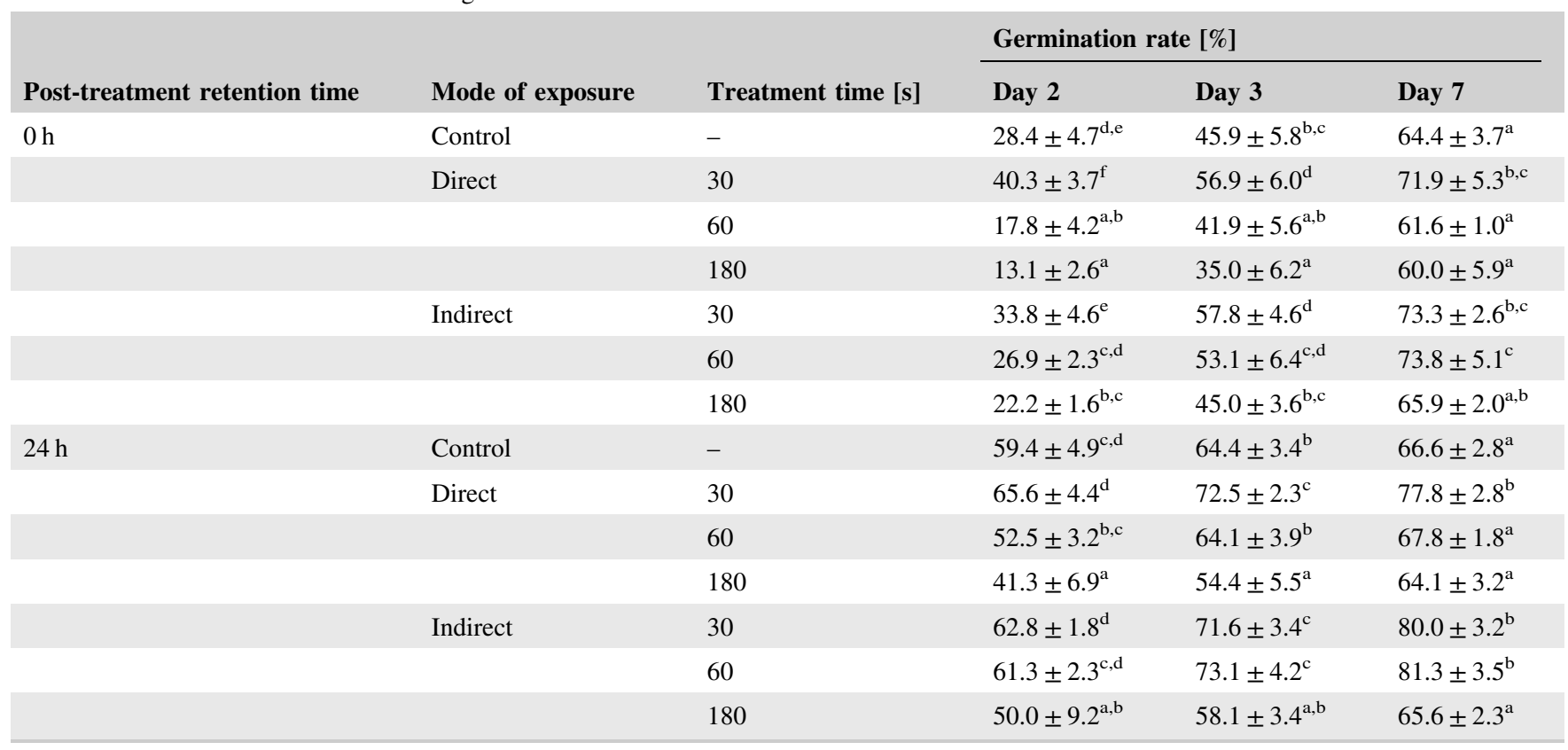

Different letters indicate significant difference between the control and ACP-treated samples within each post-treatment retention time $(p<0.05)$. Experiments were performed four times (number of seeds per experiment -80 ). 
samples over the test period. On Day 7, short duration direct ACP treatment $(30 \mathrm{~s})$ increased the germination rate by $11.2 \%$. Indirect treatments of 30 and $60 \mathrm{~s}$ enhanced germination by 13.4 and $14.7 \%$, respectively. Overall, regardless to retention time, the highest values of germination rate on Day 7 were obtained for the seeds subjected to indirect ACP treatment for $60 \mathrm{~s}$, which corresponded to 73.8 and $81.3 \%$ for 0 and $24 \mathrm{~h}$ retention time, respectively, as compared to germination rate of untreated seeds.

Similar trends were noted for the samples with a $0 \mathrm{~h}$ retention time regarding germination and SVI (Table 2), where 60 and $180 \mathrm{~s}$ of direct ACP treatment affected the parameters negatively, whereas both direct and indirect short duration ( $30 \mathrm{~s})$ treatments significantly improved the quality of the seeds by increasing their GI and SVI. For the samples subjected to plasma treatment followed by $24 \mathrm{~h}$ of retention time (Table 2) a negative effect from $180 \mathrm{~s}$ treatment (both direct and indirect) on the GI value was observed, while $30 \mathrm{~s}$ of direct ACP significantly improved the parameter by $12.3 \%$. Insignificant increases in GI were observed for 30 and $60 \mathrm{~s}$ indirect exposure - with 9.9 and $9.8 \%$, respectively. Regardless of mode of exposure, 30 and $60 \mathrm{~s}$ ACP resulted in a significant increase of SVI.

No differences between the control and treated samples were observed for shoot length of the wheat seeds without a post-treatment retention time except the sample treated directly for $30 \mathrm{~s}$ (Figure 1). In contrast, shoots of all ACPtreated samples stored for $24 \mathrm{~h}$ were significantly longer than those of untreated seeds except for samples treated directly for
$180 \mathrm{~s}$. Again, the highest increase, i.e., 25\%, was observed for seeds treated indirectly for $60 \mathrm{~s}$. Regardless of retention time, there was a significant increase in root length for all treated seeds in comparison with the control samples. It is evident that research on the gene expression and plant hormonal levels of wheat is required to elucidate the plasma interactions with a live plant system in order to explain the specific responses observed in this work, namely root elongation associated with shoot length decrease. Tailoring the plasma reactive species specificity may be a useful approach in order to understand the plant system biological responses to this technology and how to control it.

Several authors have investigated the effect of plasma on the germination of wheat, however, the results are not consistent. A number of studies reported significant improvements of wheat germination rates as a result of short plasma treatment, ${ }^{[14,38,39]}$ while in other reports such effect was not observed. ${ }^{[13,40]}$ Dobrin et al. ${ }^{[13]}$ noted that plasma had minimal effects on seeds germination rate, however, the treatment impacted the plant's roots and sprouts, which were longer and heavier than those of the untreated controls. Similarly, Šerá et al. ${ }^{[41]}$ observed that the rate of germination of ACP-treated and untreated wheat did not differ on the 8th and 12th days after planting, however, it was significantly higher for seeds subjected to plasma for $300 \mathrm{~s}$ at the beginning of the experiment (4th day). Zahoranová et al. ${ }^{[16]}$ reported that the germination rate, dry weight, and vigour of the seedlings significantly increased for plasma treatment from 20 to $50 \mathrm{~s}$ with the highest positive responses for $30 \mathrm{~s}$ of treatment time

TABLE 2 Effect of ACP treatment on germination parameters of wheat seeds

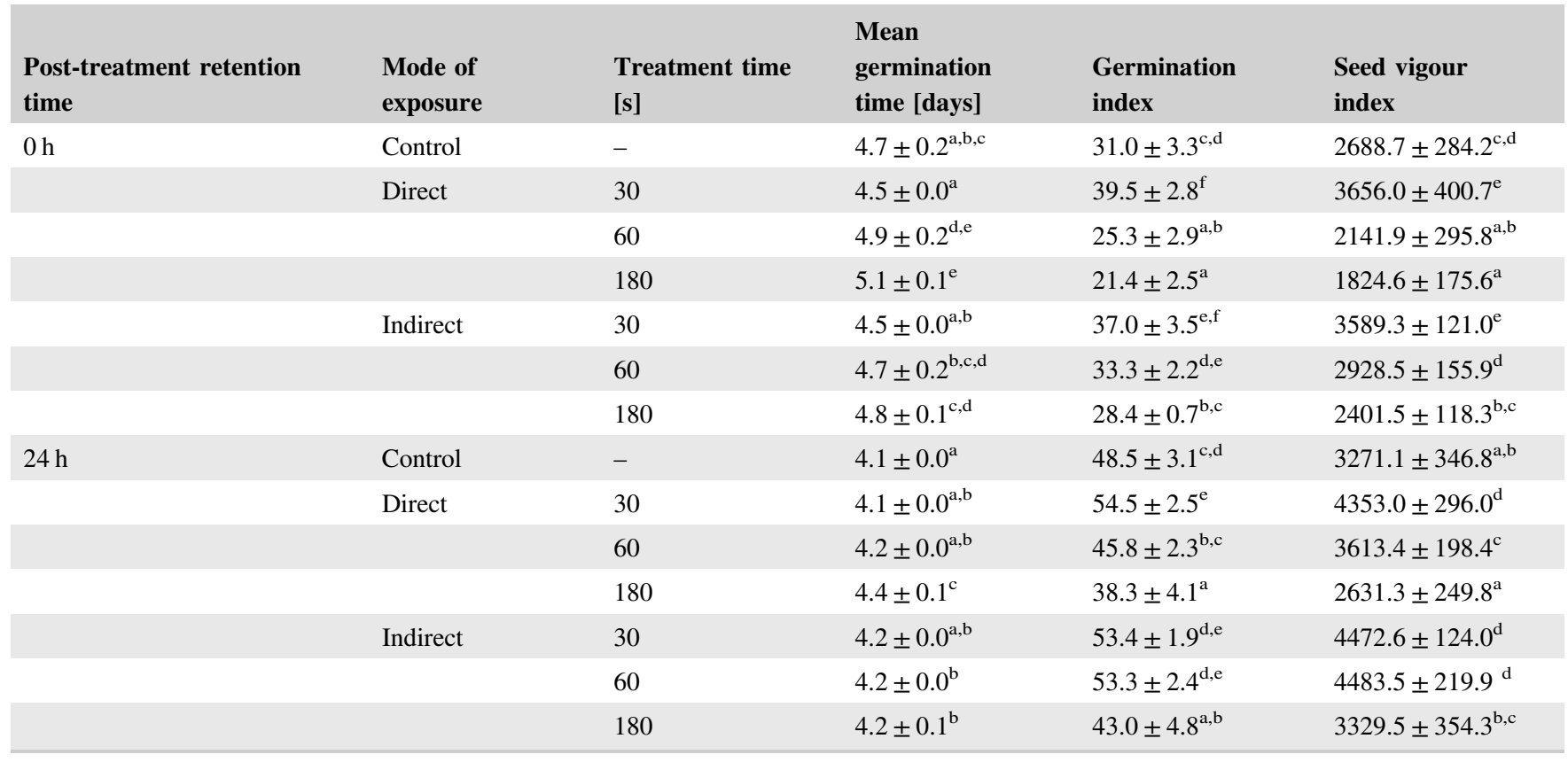

Different letters indicate significant difference between the control and ACP-treated samples within each post-treatment retention time $(p<0.05)$. Experiments were performed four times (number of seeds per experiment -80 ). 

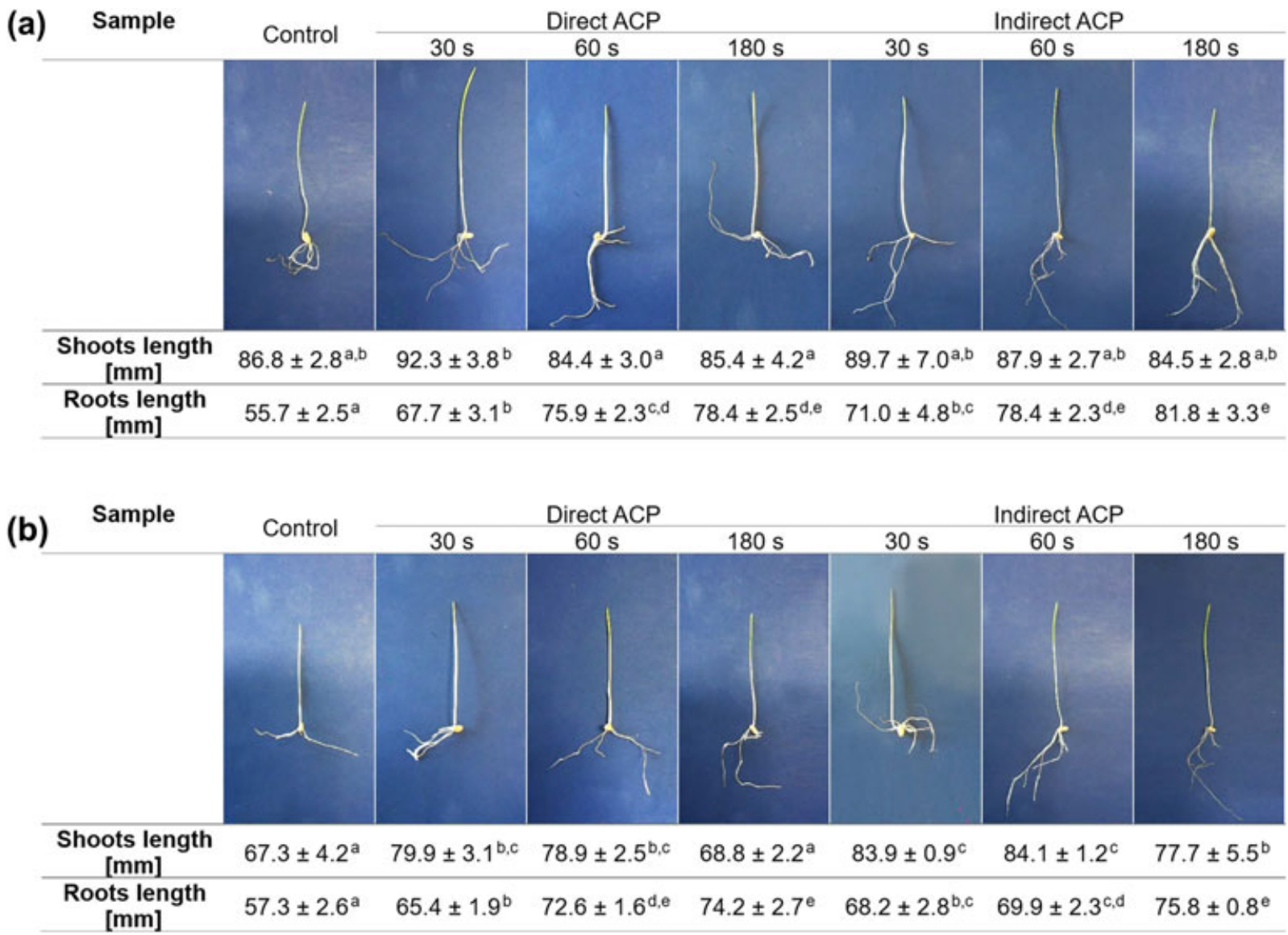

FIGURE 1 (a and b) Shoots and roots length [mm] of wheat seedlings on the 7th day after sowing. ACP treatment (a) without and (b) combined with $24 \mathrm{~h}$ post-treatment retention time. Different letters indicate significant difference between the control and ACP-treated samples within each post-treatment retention time $(p<0.05)$

(21\% higher germination rate), however, longer plasma treatments (70 and $80 \mathrm{~s}$ ) significantly inhibited all measured growth parameters in comparison to the control samples. Similarly, this work demonstrated that wheat germination and plant growth parameters can be induced with short plasma treatments $(30-60 \mathrm{~s})$. In contrast longer treatment inhibited plant formation and growth. However, other plasma processing parameters, such as mode of exposure and contact time between the plasma reactive species and seeds can also play an important role in modulating plant responses. For instance, $60 \mathrm{~s}$ of treatment in combination with indirect mode and extended retention time of $24 \mathrm{~h}$ positively influenced wheat growth parameters of germination rate, germination, and seed vigour indices. This can be attributed to the enhanced physico-chemical interactions between the seeds and the longer-lived plasma reactive species prevalent with extended contained storage time. In general, higher plasma doses (achieved with higher voltage, longer treatment time, direct mode of exposure, and extended post-treatment contact time) can be useful when microbial decontamination of seeds is required. Our earlier work clearly demonstrated high potential of ACP for the control of native microflora, pathogenic bacterial, and fungal challenge microorganisms. ${ }^{[28]}$ Therefore, taking into account results from previous work and the results of the current research, it can be concluded that short ACP treatment times can be adapted for seed germination enhancement, whereas longer treatments are needed for efficient microbial decontamination.

\subsection{Changes in the surface chemistry and characteristics of the wheat seeds after ACP treatment}

\subsection{1 | Effect on seed hydrophobicity, moisture content, and water uptake}

The changes in wetting properties of seeds surfaces due to plasma treatment were observed by several authors. Bormashenko et al. ${ }^{[21]}$ observed that the hydrophilic properties of seed increased considerably after $15 \mathrm{~s}$ of plasma treatment and noted a dramatic decrease in the apparent contact angle $115^{\circ}-0^{\circ}$. The effect on water absorption was less pronounced with the change in wettability resulting in small increases in imbibition (water uptake). In another study 
a decrease in wheat seed contact angle was also reported $\left(92 \pm 0.73^{\circ}\right.$ to $\left.53 \pm 0.85^{\circ}\right)$, accompanied by a $10-15 \%$ rise in water absorption. ${ }^{[13]}$ In our study, contact angle measurements were employed as an indicator of the effect of ACP treatment on the hydrophobicity of the wheat seed's surface (Table 3 and Figure 2). The effect of the mode of plasma exposure on the apparent contact angle values of deionized water deposited on the seed was evident regardless of the retention time. Direct plasma treatment dramatically decreased the apparent contact angles for all the treatment times used in the study $(30,60$, and $180 \mathrm{~s})$, whereas indirect ACP did not affect the surface hydrophobic properties - i.e., the water contact angle remained larger than $90^{\circ} .^{[42]}$

Changes to the surface coating after plasma treatment also can be associated with enhancement of water permeability into the seeds, which is an important factor affecting germination parameters. ${ }^{[1]}$ Water absorption (imbibition) is an essential step to ensure a nutrient supply to the germinating embryo and for generation of energy required to initiate the germination process and seedling growth. ${ }^{[43]}$ For seeds with a thick coat and low permeability, plasma treatments can improve the surface hydrophilicity and enhance water uptake, which stimulates germination.

The ability of untreated and ACP-treated wheat seeds to absorb water was tested in this study. The results for the samples with a $0 \mathrm{~h}$ retention time showed no significant differences in water uptake between plasma treated and control seeds after either 2 or $8 \mathrm{~h}$ of imbibition (Figure 3 ). However, the results obtained for ACP treatment combined with $24 \mathrm{~h}$ of retention time showed that in general the seeds treated with plasma absorbed more water than the untreated seeds (Figure 4). Water uptake of seeds treated directly for 60 and $180 \mathrm{~s}$ after $2-\mathrm{h}$ imbibition was significantly higher than that of control samples with 7.12 and $6.90 \mathrm{mg}$ of water per seed, respectively, while untreated seeds took up on average $5.23 \mathrm{mg} / \mathrm{seed}$. The changes in water uptake were more evident after $8 \mathrm{~h}$ of imbibition where the control seeds took up $10.02 \mathrm{mg} / \mathrm{seed}$ of water. A significant increase in water uptake was noted for seeds treated for 60 and $180 \mathrm{~s}$, both directly (12.12 and $12.39 \mathrm{mg} / \mathrm{seed}$, respectively) and indirectly (11.72 and $12.06 \mathrm{mg} / \mathrm{seed}$, respectively). The capacity of seeds to uptake water is an essential parameter that will determine seed germination and yields. An increase of water uptake of wheat seeds as the result of plasma treatment was observed in previous work. ${ }^{[16]}$ Current study demonstrates that higher plasma doses can affect physical characteristics of seeds resulting in an increased water uptake and the contact angle, which, however, will not always be associated with an improved seeds germination rates.

ACP treatment alone or combined with $24 \mathrm{~h}$ of posttreatment retention time did not affect the moisture content of the wheat seeds significantly (Table 3 ). It was recorded that temperature of the samples treated directly increased on average by $1.4,2.9$, and $5.9^{\circ} \mathrm{C}$ for 30,60 , and $180 \mathrm{~s}$ of treatment, respectively, however, a slight temperature increase of the samples did not cause a decrease of seeds' weight by possible evaporation of water. No changes of temperature were noted for the samples subjected to indirect

TABLE 3 Effect of ACP treatment on properties of wheat seeds

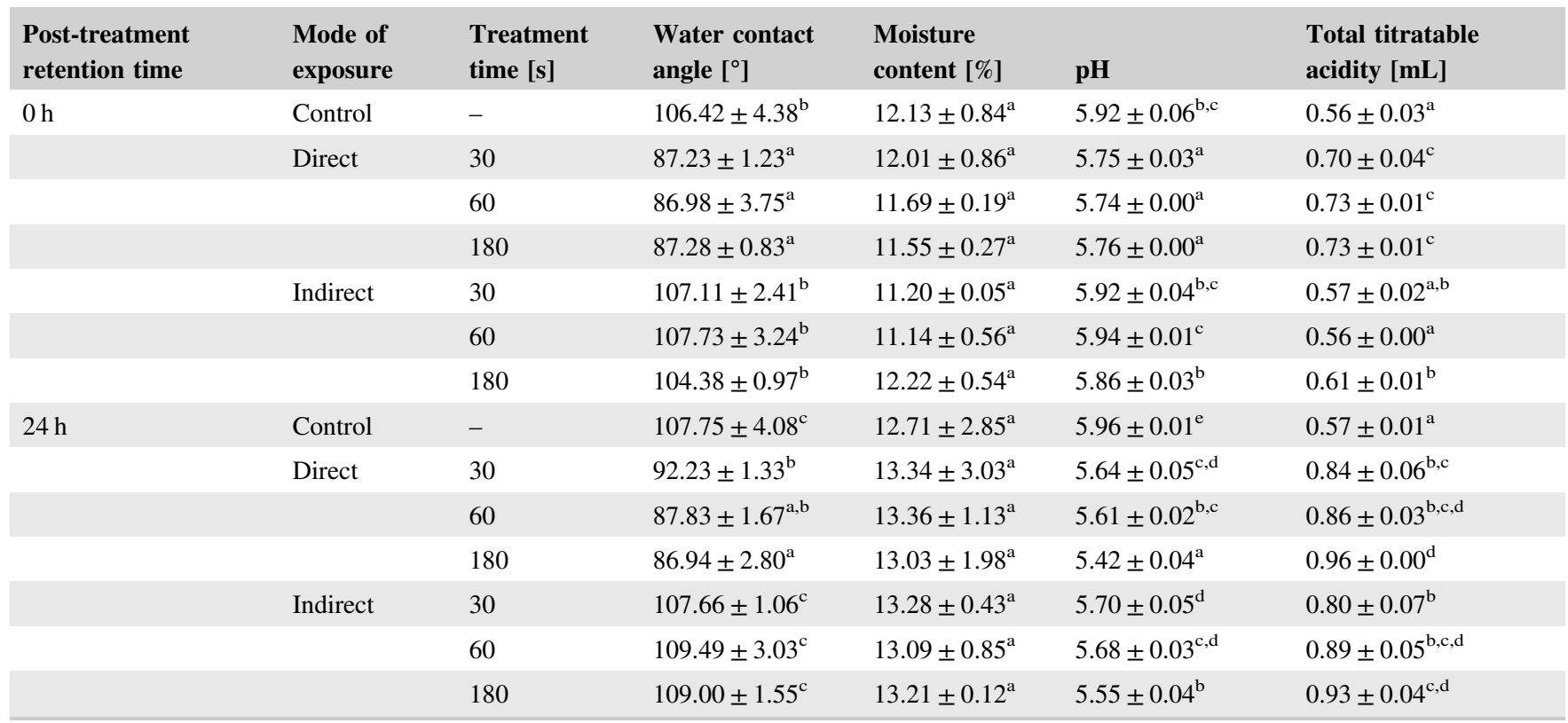

Different letters indicate significant difference between the control and ACP-treated samples within each post-treatment retention time $(p<0.05)$. Experiments were performed three times (number of seeds per experiment in water contact angle measurements - 3; number of seeds per experiment in moisture content, pH and total titratable acidity measurements $-2 \mathrm{~g}$, i.e., $\sim 60$ seeds). 
(a)
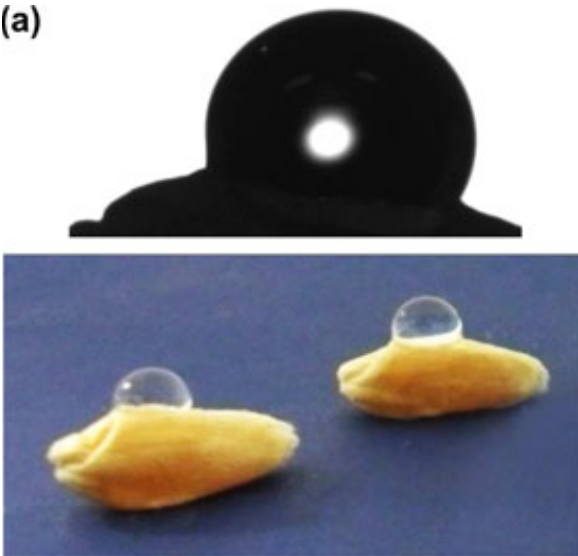

(b)

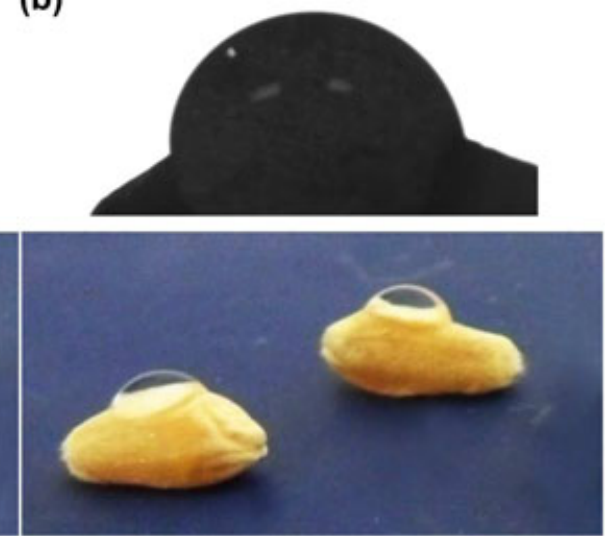

FIGURE 2 (a and b) Droplets of water deposited on wheat seed: (a) untreated and (b) ACP-treated directly for $180 \mathrm{~s}$ (without post-treatment retention time)

treatment. It should be noted that the moisture content values of the samples stored for $24 \mathrm{~h}$ at $15^{\circ} \mathrm{C}$ were slightly higher than those of the samples assessed immediately after the treatment, which could be due to water condensation inside the incubator in which the samples were stored. Similarly, Selcuk et al. ${ }^{[40]}$ reported an insignificant increase or decrease $( \pm 0.9 \%)$ in moisture content of wheat treated with air gases or $\mathrm{SF}_{6}$ plasma.

(a)

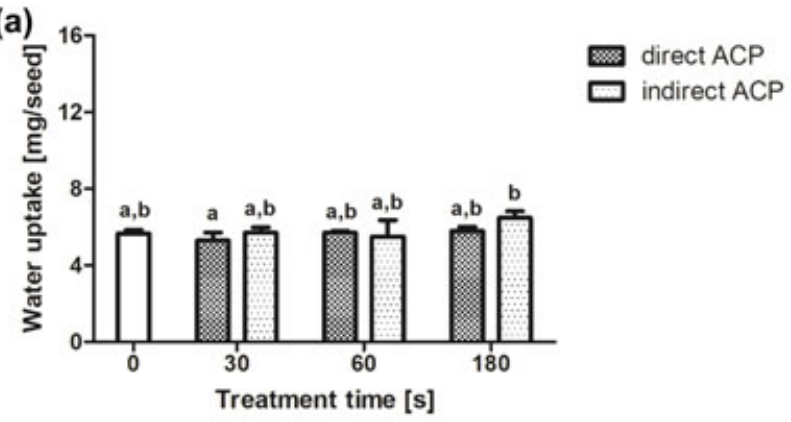

(b)

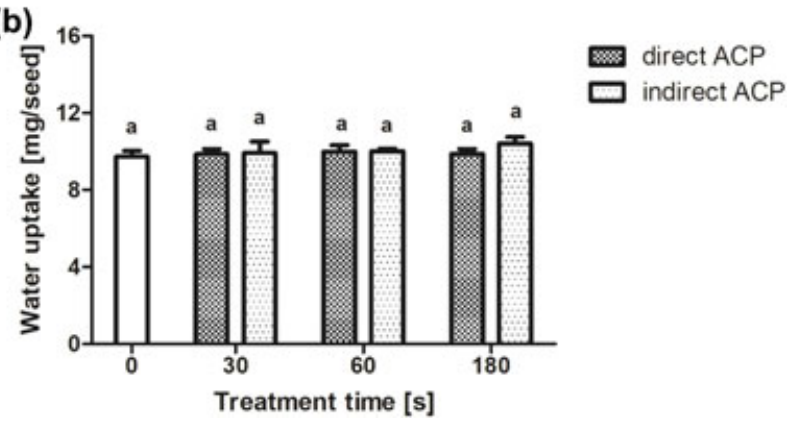

FIGURE 3 (a and b) Effect of ACP treatment without posttreatment retention time on water uptake of wheat seeds: (a) 2 and (b) $8 \mathrm{~h}$ of imbibition time. Vertical bars represent standard deviation. Different letters indicate significant difference between the control and ACP-treated samples within each post-treatment retention time $(p<0.05)$. Experiments were performed three times (number of seeds per experiment $-2 \mathrm{~g}$, i.e., $\sim 60$ seeds)

\subsection{2 $\mid$ Effect on seeds pH and acidity}

Changes in $\mathrm{pH}$ values and TTA of wheat seeds after plasma treatment were investigated and a correlation of these two parameters measured within the samples with the same posttreatment retention time were observed (Table 3). For the samples with $0 \mathrm{~h}$ retention time, a significant decrease of $\mathrm{pH}$ and increase of TTA were noted for all samples treated with
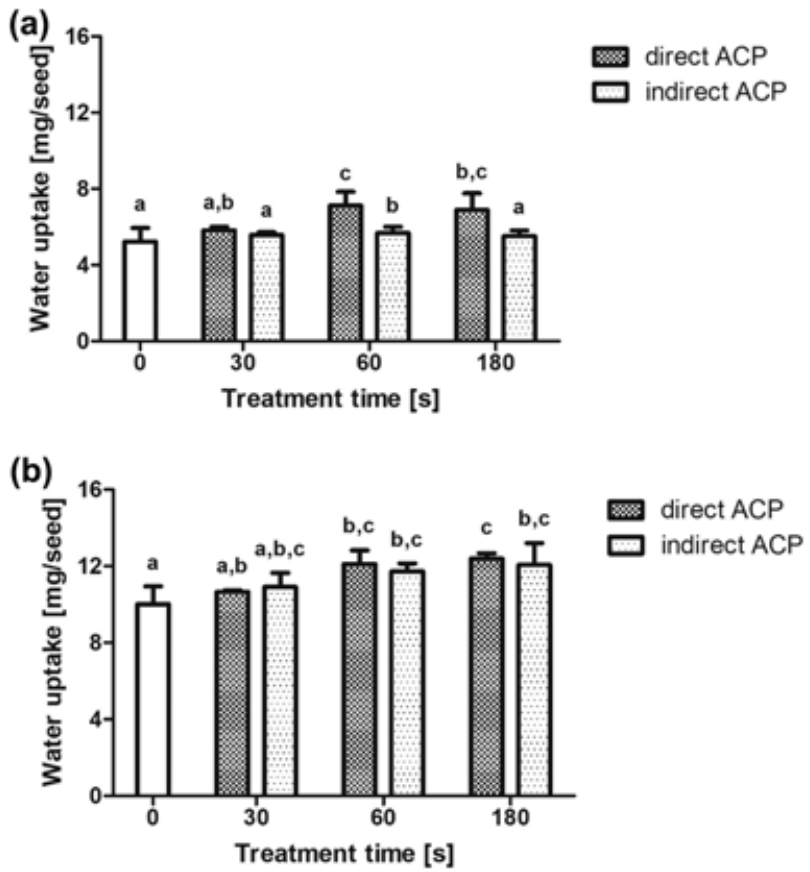

FIGURE 4 (a and b) Effect of ACP treatment combined with $24 \mathrm{~h}$ post-treatment retention time on water uptake of wheat seeds: (a) 2 and (b) $8 \mathrm{~h}$ of imbibition time. Vertical bars represent standard deviation. Different letters indicate significant difference between the control and ACP-treated samples within each post-treatment retention time $(p<0.05)$. Experiments were performed three times (number of seeds per experiment $-2 \mathrm{~g}$, i.e., $\sim 60$ seeds) 
the direct mode of plasma exposure. The longest indirect treatment used in the study, i.e., $180 \mathrm{~s}$, also significantly increased seed TTA. Extending the retention time up to $24 \mathrm{~h}$ resulted in a significant decrease of $\mathrm{pH}$ (to $\mathrm{pH} 5.42$ after direct $180 \mathrm{~s}$ treatment and $24 \mathrm{~h}$ retention) and increase of acidity for all the ACP-treated seeds. Similarly, Lee et al. ${ }^{[44]}$ observed reduced $\mathrm{pH}$ of brown rice due to the plasma treatment. This could be attributed to longer contact time between the seeds and generated plasma reactive nitrogen species, which could react with seeds components thereby lowering the seeds $\mathrm{pH}$. In other studies, no significant differences in $\mathrm{pH}$ values after cold plasma treatment were observed for other foods such as meat, ${ }^{[45]}$ cherry tomatoes, ${ }^{[46]}$ and white grape juice. ${ }^{[4]}$

\subsection{3 | Effect of ACP treatment on concentrations of $\mathrm{H}_{2} \mathrm{O}_{2}, \mathrm{NO}_{2}{ }^{-}, \mathrm{NO}_{3}{ }^{-}$, and MDA in seeds}

In a study performed by Bormashenko et al., ${ }^{[21]}$ TOF-SIMS spectroscopy showed a significant increase in the concentration of oxygen- and nitrogen-containing groups at the surface of the plasma-treated seeds of lentils, beans, and wheat. Similarly, oxidation of the outer layers of the seed coat and pericarp, as well as formation of oxidized nitrogen species on the Quinoa seed's surface after plasma treatment, were observed by Gómez-Ramírez et al. ${ }^{[48]}$ In the present work, changes in the surface chemistry of the wheat seeds exposed to plasma were investigated as to our knowledge there have been no previous reports regarding these chemical parameters for wheat. In this part of the study, samples which showed an improvement in the germination parameters, i.e., ACP-treated directly or indirectly for $30 \mathrm{~s}$ were compared to the samples with inhibited germination (ACP-treated directly for $180 \mathrm{~s}$ ) and untreated samples.

It was found that direct exposure to plasma without retention time results in a gradual increase of the content of nitrites in the seeds, with significant increases in the samples treated for 30 and $180 \mathrm{~s}$. For seeds stored for $24 \mathrm{~h}$ after the treatment, only the longest treatment time resulted in a significant increase of $\mathrm{NO}_{2}^{-}$(Figure 5a), which was associated with growth inhibition as demonstrated in germination tests. With respect to the control samples, slightly higher levels of nitrates were observed for all the tested samples subjected to plasma when the treatment was combined with extended time of exposure to reactive species, i.e., $24 \mathrm{~h}$ (Figure 5b). Our results suggest that too high concentrations of nitrogen compounds in seeds negatively affect their germination. Iranbakhsh et al. ${ }^{[49]}$ investigated the effect of nitrogen and helium plasma on wheat seeds - growth inhibition symptoms of the seeds were observed in samples exposed to nitrogen plasma, attributed to the higher amount of produced nitric oxide in N-plasma compared with He-plasma. Overall, results obtained in this study reveal important
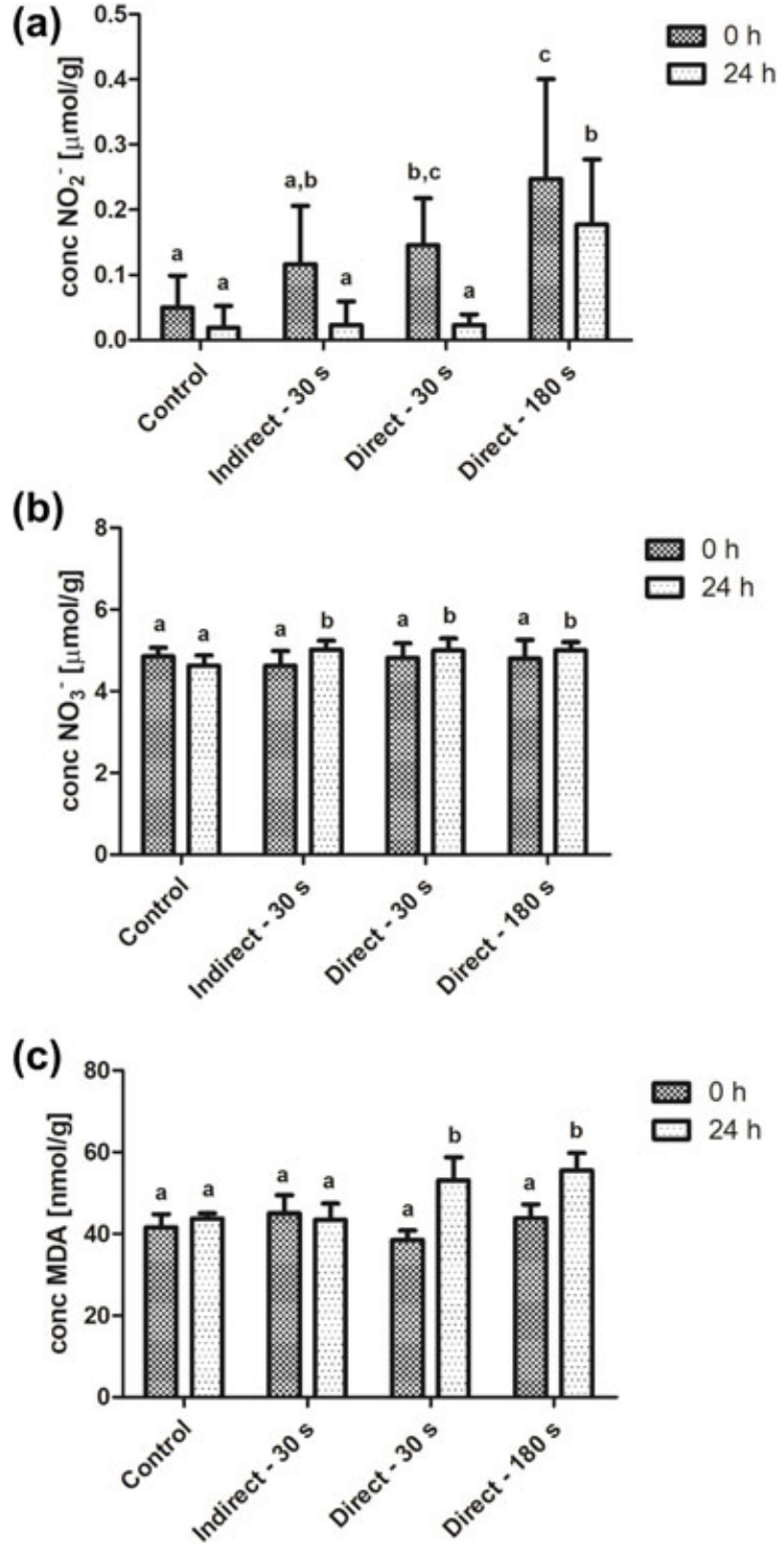

FIGURE 5 (a-c) The concentrations of (a) $\mathrm{NO}_{2}{ }^{-}$, (b) $\mathrm{NO}_{3}{ }^{-}$, and (c) MDA in untreated and ACP-treated wheat seeds (post-treatment retention time: 0 or $24 \mathrm{~h}$ ). Vertical bars represent standard deviation. Different letters indicate significant difference between the control and ACP-treated samples within each post-treatment retention time $(p<0.05)$. Experiments were performed three times (number of seeds per experiment -2 g, i.e., $\sim 60$ seeds)

modifications of the surface chemistry of the seeds - changes in concentration levels of nitrites and nitrates should be therefore monitored due to potential accumulation of nitrogen compounds in food products subjected to plasma treatment. $^{[24]}$

The values of MDA are the indicator of lipid peroxidation - an increase of MDA content is associated with formation of reactive oxygen species (ROS) and is often used as an 

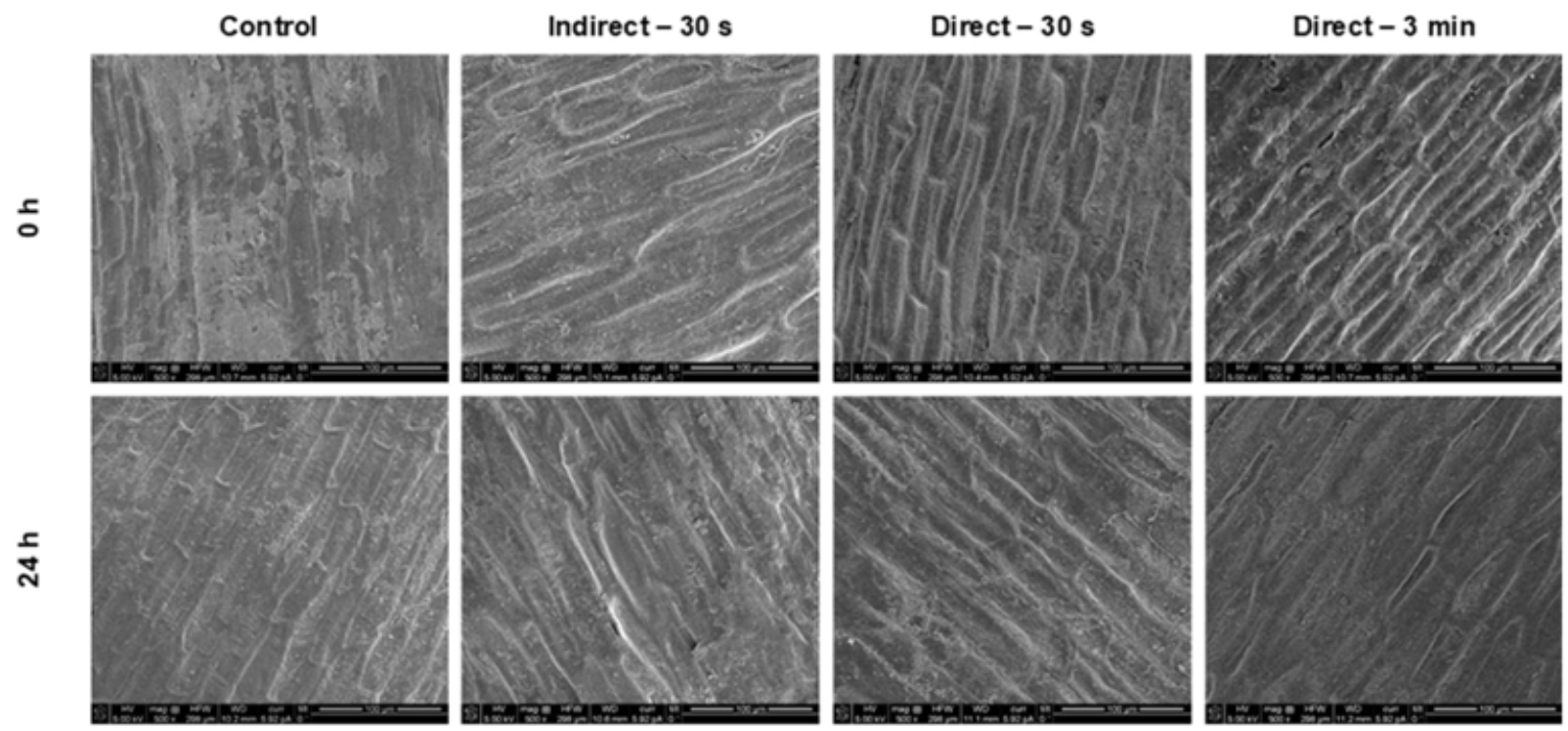

FIGURE 6 SEM images of untreated and ACP-treated wheat seeds without (top panel) and combined with $24 \mathrm{~h}$ post-treatment retention time (bottom panel). Magnification: 500X; scale bar: $100 \mu \mathrm{m}$

indicator of plant stress. ${ }^{[50,51]}$ In our study, significant changes in the concentrations of MDA were observed only after direct ACP treatments combined with $24 \mathrm{~h}$ retention time - an increase of MDA levels by 27.8 and $33.8 \%$ was recorded for 30 and $180 \mathrm{~s}$, respectively (Figure 5c). These changes showed that mode of plasma exposure was a crucial factor of lipid peroxidation. As mentioned previously, for direct plasma treatment the seeds were placed directly between the electrodes, therefore, they were exposed to all generated reactive species, such as charged particles, positive and negative ions, electrons, free radicals, excited and nonexcited molecules and atoms, heat and UV photons, leading to increased lipid peroxidation. ${ }^{[52]}$ For indirect mode of plasma exposure the samples were placed outside of the area of plasma discharge - the charged particles did not contact them directly during ACP treatment as they recombine before reaching the samples and possibly they have been affected mainly by long-lived radicals. ${ }^{[53]}$

As exposure to plasma could result in the generation of relatively long-lived secondary products on the surface of wheat seeds subjected to plasma, it is important to investigate the safety of this technology for food and agricultural applications. In our study the levels of $\mathrm{H}_{2} \mathrm{O}_{2}-$ a biologically active compound with demonstrated anti-microbial and cytotoxic activity, were measured. It was found that $\mathrm{H}_{2} \mathrm{O}_{2}$ was not detected in either untreated or ACP-treated seeds, regardless of the retention time or the use of atmospheric air as the feed gas.

\subsection{4 $\mid$ SEM analysis}

It has been observed that plasma can induce changes in seed surfaces with erosion of the wheat seed coat. ${ }^{[41]}$ Zahoranová et al. ${ }^{[16]}$ suggested that an increase in the germination and growth development after plasma treatment could be due to the effects on the tissue structures that leads to the transport of essential substances through the channels induced on the cell membranes. In our study SEM analysis of wheat seeds was performed to investigate the surface topography, which demonstrated no visible differences between untreated and ACP-treated wheat seeds (Figure 6).

\section{4 | CONCLUSION}

The results reported in this study indicate that short plasma treatments (30-60 s) can significantly improve germination properties of the wheat seeds and the growth parameters of the seedlings. These effects were a function of the mode of plasma exposure as well as post-treatment retention time in a contained reactor. Indirect plasma treatment for $60 \mathrm{~s}$ combined with $24 \mathrm{~h}$ post-treatment contact time between the plasma generated species and the seeds was the most effective; which enhanced germination rate of wheat by $14.7 \%$ as compared with untreated controls. Other growth parameters, such as GI and SVI, were also improved. However, adverse effects on seeds germination parameters were observed when longer plasma treatment (180 s) was applied, irrespective of the post-treatment retention time. The mode of action of plasma on seeds resulting in germination improvement may be correlated to changes of seeds surface chemistry. However, the levels of nitrites and nitrates should be monitored due to the negative impact of high levels of nitrogen compounds on seeds germination rates. The results indicate that cold plasma has potential as an effective 
alternative to traditional pre-sowing seed treatments used in agriculture for germination enhancement.

\section{ACKNOWLEDGMENT}

This work was conducted with the financial support of Science Foundation Ireland (SFI) under Grant Number 14/IA/ 2626.

\section{ORCID}

Daniela Boehm iD http://orcid.org/0000-0003-3188-5115

\section{REFERENCES}

[1] P. R. Shewry, J. Exp. Bot. 2009, 60, 1537.

[2] Food and Agriculture Organization of the United Nations. FAOSTAT Database. http://www.fao.org/faostat/en/ (accessed on August 17th, 2018).

[3] P. Kumar, R. Yadava, B. Gollen, S. Kumar, R. Verma, S. Yadav, Life Sci. Med. Res. 2011, 22, 1.

[4] M. S. Sibian, D. C. Saxena, C. S. Riar, J. Sci. Food Agric. 2017, 97, 4643.

[5] A. Enghiad, D. Ufer, A. M. Countryman, D. D. Thilmany, Int. J. Agron. 2017, 3931897. https://doi.org/10.1155/2017/3931897

[6] C. Weigand, U.S. Wheat Associates. 2011, 1-14. https://docplayer. net/268765-Wheat-import-projections-towards-2050-chad-weigandmarket-analyst.html

[7] S. J. Goussous, N. H. Samarah, A. M. Alqudah, M. O. Othman, Exp. Agric. 2010, 46, 231.

[8] A. Gholami, S. Sharafi, H. Abbasdokht, World Acad. Sci. Eng. Technol. 2010, 4, 1385.

[9] S. Pietruszewski, K. Kania, Int. Agrophys. 2010, 24, 297.

[10] A. Borzouei, M. Kafi, H. Khazaei, B. Naseriyan, A. Majdabadi, Pak. J. Bot. 2010, 42, 2281.

[11] M. Melki, A. Marouani, Environ. Chem. Lett. 2010, 8, 307.

[12] H. Mahmoodzadeh, R. Aghili, J. Clin. Health Sci. 2014, 4, 29.

[13] D. Dobrin, M. Magureanu, N. B. Mandache, M.-D. Ionita, Innov. Food Sci. Emerg. Technol. 2015, 29, 255.

[14] J. Jiang, X. He, L. Li, J. Li, H. Shao, Q. Xu, R. Ye, Y. Dong, Plasma Sci. Technol. 2014, 16, 54.

[15] B. Šerá, M. Šerý, V. Štrañák, P. Špatenka, M. Tichý, Plasma Sci. Technol. 2009, 11, 750.

[16] A. Zahoranova, M. Henselova, D. Hudecova, B. Kalinakova, D. Kovacik, V. Medvecka, M. Cernak, Plasma Chem. Plasma Process. 2015, 36, 397.

[17] L. K. Randeniya, G. J. J. B. De Groot, Plasma Process. Polym. 2015, 12, 608 .

[18] T. Ohta, in Cold Plasma in Food and Agriculture, 1st ed. (Eds: N. N. Misra, O. K. Schlüter, P. J. Cullen), Academic Press, San Diego, CA 2016.

[19] M. Ito, J.-S. Oh, T. Ohta, M. Shiratani, M. Hori, Plasma Process. Polym. 2017, 15, e1700073.

[20] R. Brandenburg, A. Bogaerts, W. Bongers, A. Fridman, G. Fridman, B. R. Locke, V. Miller, S. Reuter, M. Schiorlin,
T. Verreycken, K. K. Ostrikov, Plasma Process. Polym. 2018, 16, e1700238.

[21] E. Bormashenko, R. Grynyov, Y. Bormashenko, E. Drori, Sci. Rep. 2012, 2, 3 .

[22] J. Kim, P. Puligundla, C. Mok, J. Sci. Food Agric. 2017, 97, 128.

[23] T. Stolárik, M. Henselová, M. Martinka, O. Novák, A. Zahoranová, M. Černák, Plasma Chem. Plasma Process. 2015, 35, 659.

[24] P. Bourke, D. Ziuzina, D. Boehm, P. J. Cullen, K. Keener, Trends Biotechnol. 2018, 36, 615.

[25] P. J. Cullen, J. Lalor, L. Scally, D. Boehm, V. Milosavljević, P. Bourke, K. Keener, Plasma Process. Polym. 2018, 15, 1.

[26] S. K. Pankaj, N. N. Misra, P. J. Cullen, Innov. Food Sci. Emerg. Technol. 2013, 19, 153.

[27] T. Moiseev, N. N. Misra, S. Patil, P. J. Cullen, K. M. Keener, J. P. Mosnier, Plasma Sources Sci. Technol. 2014, 23, 065033.

[28] A. Los, D. Ziuzina, S. Akkermans, D. Boehm, P. J. Cullen, J. Van Impe, P. Bourke, Food Res. Int. 2018, 106, 509.

[29] H. Manmathan, D. Shaner, J. Snelling, N. Tisserat, N. Lapitan, J. Exp. Bot. 2013, 64, 1381.

[30] Seed Vigor Testing Handbook. AOSA, Ithaca, NY, USA. (Contribution to the Handbook on Seed Testing, 32), 1983.

[31] J. Liu, Q. Wang, Đ. Karagić, X. Liu, J. Cui, J. Gui, M. Gu, W. Gao, Sci. Rep. 2016, 6, 22403.

[32] S. K. Pankaj, C. Bueno-Ferrer, N. N. Misra, L. O'Neill, B. K. Tiwari, P. Bourke, P. J. Cullen, LWT - Food Sci. Technol. 2015, 63, 1076.

[33] J. Y. Ahn, D. Y. Kil, C. Kong, B. G. Kim, Asian-Australasian J. Anim. Sci. 2014, 27, 1615.

[34] D. Boehm, C. Heslin, P. J. Cullen, P. Bourke, Sci. Rep. 2016, $6,1$.

[35] P. Lu, D. Boehm, P. Bourke, P. J. Cullen, Plasma Process. Polym. 2017, 14, 1 .

[36] R. L. Heath, L. Packer, Arch. Biochem. Biophys. 1968, 125, 189.

[37] D. Ziuzina, S. Patil, P. J. Cullen, K. M. Keener, P. Bourke, Food Microbiol. 2014, 42, 109.

[38] Y. Li, T. Wang, Y. Meng, Plasma Chem. Plasma Process. 2017, 37, 1621.

[39] Y. Meng, G. Qu, T. Wang, Plasma Chem. Plasma Process. 2017, 37, 1105.

[40] M. Selcuk, L. Oksuz, P. Basaran, Bioresour. Technol. 2008, 99, 5104.

[41] B. Šerá, P. Špatenka, M. Šerý, N. Vrchotová, I. Hrušková, IEEE Trans. Plasma Sci. 2010, 38, 2963.

[42] K. Y. Law, J. Phys. Chem. Lett. 2014, 5, 686.

[43] A. T. Adebe, A. T. Modi, Res. J. Seed Sci. 2009, 2, 23.

[44] K. H. Lee, H.-J. Kim, K. S. Woo, C. Jo, J.-K. Kim, S. H. Kim, H. Y. Park, S.-K. Oh, W. H. Kim, LWT-Food Sci. Technol. 2016, 73, 442.

[45] N. Ulbin-Figlewicz, E. Brychcy, A. Jarmoluk, J. Food Sci. Technol. 2015, 52, 1228.

[46] N. N. Misra, K. M. Keener, P. Bourke, J. P. Mosnier, P. J. Cullen, J. Biosci. Bioeng. 2014, 118, 177.

[47] S. K. Pankaj, Z. Wan, W. Colonna, K. M. Keener, J. Sci. Food Agric. 2017, 97, 4016.

[48] A. Gómez-Ramírez, C. López-Santos, M. Cantos, J. L. García, R. Molina, J. Cotrino, J. P. Espinós, A. R. González-Elipe, Sci. Rep. 2017, 7, 1 . 
[49] A. Iranbakhsh, M. Ghoranneviss, Z. Oraghi Ardebili, N. Oraghi Ardebili, S. Hesami Tackallou, H. Nikmaram, Biol. Plant 2017, 61, 702.

[50] M. Filek, S. Walas, H. Mrowiec, E. Rudolphy-Skórska, A. Sieprawska, J. Biesaga-Kościelniak, Acta Physiol. Plant 2012, 34, 985.

[51] M. Kurdziel, M. Filek, M. Labanowska, J. Sci. Food Agric. 2018, 98, 2607.

[52] D. Ziuzina, S. Patil, P. J. Cullen, K. M. Keener, P. Bourke, J. Appl. Microbiol. 2013, 114, 778.

[53] M. Laroussi, IEEE Trans. Plasma Sci. 2009, 37, 714.

How to cite this article: Los A, Ziuzina D, Boehm D, Cullen PJ, Bourke P. Investigation of mechanisms involved in germination enhancement of wheat (Triticum aestivum) by cold plasma: Effects on seed surface chemistry and characteristics. Plasma Process Polym. 2019;16:e1800148, https://doi.org/10.1002/ppap.201800148 